\title{
Sabiduría y apoliticidad en el pensamiento de Epicuro
}

Recibido: 27/07/2018. Aceptado: 07/12/2018

\section{Resumen}

Entre las cartas y fragmentos conservados de Epicuro queda claro que, en su concepción, el sabio debe apartarse de la vida política (SV 58, fr.8). Por otro lado, los filósofos necesitan de una comunidad de amistad en el marco de la cual sus reflexiones se desarrollen máximamente. Nos ocuparemos aquí de revisar la manera en que deben entenderse las modulaciones de la pretendida apoliticidad, en conjunción con la philía. Propondremos que, entre las preocupaciones de Epicuro, no estuvo la el esclarecer el tipo de vínculo que debe haber entre la comunidad de amistad y la pólis en su conjunto, procurando sólo señalar el perjuicio que causa al sabio este último ámbito, y algunas vías por las cuales puede mantener su relación con él, en orden de favorecer su tranquilidad.

PALABRAS CLAVE: Epicuro, amistad, política, ataraxía, prudencia.

\section{Wisdom and non-political involvement in Epicurus' thought}

\begin{abstract}
Among the letters and fragments preserved of Epicurus' thought, it is clear that he believes that the wise man must live apart from political involvement (SV 58, fr. 8). On the other hand, Epicurean philosophers need a community of friends in order to allow their reflections to fully develop. Our aim will be to evaluate the way in which the modulations of Epicurus' supposed apolitical position must be understood, in conjunction with philia. We shall propose that among Epicurus' concerns was not that of establishing the kind of link that must exist between the community of friendship and the polis as a whole, and that he simply aims to point out the harm that an active political involvement
\end{abstract}


causes to the wise man, and to give some indications on how to remain involved with the polis, but only insofar as it is convenient to preserve his ataraxía.

KEYWORDS: Epicurus, friendship, politics, ataraxía, wisdom.

En la sentencia vaticana ${ }^{1} 58$ Epicuro declara que "Nos debemos liberar a nosotros mismos de la prisión de los asuntos habituales y políticos", idea que aparece reafirmada -entre otros- en el fragmento 8: "<el sabio> tampoco participará en política". El ámbito de la pólis aparece, en el marco de su pensamiento, como un campo disruptor de la ataraxía establecido como télos de la vida humana, ya que el filósofo parece pensar la política esencialmente como un cúmulo de demandas y de contradicciones. Por otro lado, se conservan numerosos pasajes y sentencias -Carta a Meneceo 129, GV 39, 23, MC 27, etc.-, en los que Epicuro valora la amistad como una relación sustancial con la vida filosófica, sostenedora de una actividad reflexiva constante y permanente; la philía no sólo liga a los hombres y les provee seguridad en la perspectiva futura, sino que proporciona una estabilidad emocional que potencia la vida especulativa. Estos dos modos de vinculación intersubjetiva aquí valorados en oposición -i.e. la comunidad de amistad aconsejada y la vida política desestimada- esbozan una tensión en la apreciación epicúrea de la vida relacional. Adicionalmente, la vida en soledad también es criticada, y está entre las formas existenciales que el sabio debe evitar.

En este marco problemático, abriremos dos preguntas acerca de la manera en que deben entenderse las modulaciones de esta pretendida apoliticidad: (1) ¿qué características de las relaciones de amistad la eximen de los perjuicios de la vida política, haciéndola preferible a ésta?; (2) ¿subsistiría la comunidad de amistad, sin el supuesto de una comunidad política que la enmarque? Nos ocuparemos entonces de repensar el problema político a partir de una selección de fragmentos y sentencias de Epicuro, e intentaremos concluir acerca de la inconsistencia aparente entre estos dos ámbitos: el de la philía y el político. Consideraremos la idea de que el filósofo no se preocupó por lo que hubiera sucedido en caso de que su pretensión fuera universalizada y que, dadas las condiciones de Atenas en que vivió, donde la pólis proveía ciertamente de un contexto de relativa paz para que la comunidad de amistad fuera viable, su propuesta se limitó a declarar cuál era la mejor versión de la práctica filosófica, desentendiéndose de cuestiones de contexto. Dicho de otro modo, Epicuro no se preocupó por que todo el mundo fuera filósofo; pero, en caso de que lo fuera, advirtió que las circunstancias óptimas para la especulación se dan sólo en una comunidad cerrada y de iguales.

\section{El pensamiento hedonista de Epicuro y la amistad}

En la Carta a Meneceo Epicuro desarrolla el valor que para él tiene el placer, y explica cuáles son los cuatro remedios que ayudan al hombre a sobreponerse de las peores enfermedades que pueden aquejarlo: las provenientes de los temores. ${ }^{2}$ En su argumentación sitúa la actividad filosófica como la única que

1 Gnomologia o Sentencia Vaticana será en adelanta GV; Máximas Capitales, MC. Tomaremos las traducciones propuestas por E. Bieda (2015), salvo aclaración contraria.

2 Tetraphármakon o 'cuádruple remedio' es el nombre que los epicúreos han dado a estos argumentos, remedios para los temores humanos. Los seguidores de Epicuro han tomado el nombre de un remedio efec- 
permitirá llegar a la ataraxía buscada; en su modo de ver las cosas, no hay imperturbabilidad fuera de la virtud en general y de la prudencia en particular, que es incluso más fundante que la filosofía.

\begin{abstract}
El principio de todo esto y el mayor bien es la prudencia (phrónesis). Por eso, más preciada incluso que la filosofía resulta ser la prudencia, de la cual nacen todas las demás virtudes, pues ella nos enseña que no es posible vivir placenteramente sin [vivir] juiciosa, honesta y justamente, <ni [vivir de manera] juiciosa, honesta y justa> sin [vivir] placenteramente. En efecto, las virtudes son connaturales (sympephýkasi) con el vivir placentero y el vivir placentero es inseparable (akhóriston) de ellas. (Carta a Men. 132)
\end{abstract}

De entre las virtudes, en la phrónesis se resuelve la excelencia toda, porque es la que permite elegir y rechazar con fundamento; es arkhè pánton y en consecuencia resulta lo más honroso (timióteron; 132) para el hombre. Es el conocimiento del límite; por eso permite decidir, mediante un cálculo (logismós), lo mejor para la vida en su conjunto: aquello en lo que encontramos el mejor placer. Las elecciones pueden estar guiadas por opiniones falsas, y es posible entonces elegir algo que no conlleve realmente placer; frente a este riesgo, sólo el cálculo prudente evita la perturbación y la perdición del alma en elecciones ineficaces.

El placer, al que el pensador dedica prácticamente toda la carta, es concebido como connatural (129: syngenikós, pephykuîa; 130: symmetrései) al hombre; señala diferencias entre el goce del alma y el del cuerpo; es incluso pasible de ser modelado a partir de la austeridad, como leemos en los parágrafos 130-131 de la misma epístola:

\begin{abstract}
Y estimamos la autosuficiencia (autárkeia) como un gran bien, no para que en todo momento nos sirvamos de poco, sino para que, si no tenemos mucho, con poco nos sirvamos, enteramente persuadidos de que gozan más dulcemente de la abundancia los que menos requieren de ella, y que todo lo natural es fácil de lograr, pero que lo vano es difícil.
\end{abstract}

Esta especie de entrenamiento en lo mínimo orienta el disfrute humano hacia su acrecentamiento. Dado que para Epicuro hay cosas en nuestra vida que escapan a la voluntad -la týkhe, la suerte, tanto como la heimarméne, el destino-, la práctica en la austeridad aseguraría un margen firme de placer, pues si estamos acostumbrados a disponer de lo mínimo, cuando la suerte nos someta a situaciones adversas, podremos sin duda sobrellevarlas con una mínima afectación. Contrariamente, poblar la vida de goces crecientes, buscando ampliar todo el tiempo el límite del placer, ${ }^{3}$ constituye para el hombre una trampa, ya que, por un lado, se hará máximamente dependiente del objeto de deseo $\mathrm{y}$, por otro, no podrá contentarse con poco. La áskesis en la morigeración del disfrute es entonces un paso importante en la consecución de la imperturbabilidad. La exhortación a practicar la filosofía tiene como fin hacer consciente a Meneceo de la necesidad de ejercitarse (123: prâtte kai meléta), acostumbrarse (124: synéthize), recordar (127: mnemoneutéon), reflexionar (127: analogistéon; 135: meléta) en este cálculo prudente, único camino que puede conducir al hombre al mejor de los modos posibles de vida.

tivamente existente en la época, compuesto de cera, sebo, pez y resina, cuyo efecto purgante era conocido. La naturaleza curativa de la filosofía queda así establecida en este paralelo. Cfr. Oyarzún (1999:406).

3 Esta posición está representada, por ejemplo, en la pretensión de un personaje como Calicles, del diálogo Gorgias de Platón, cuyo hedonismo proclama la necesidad de hacer crecer el deseo todo cuanto sea posible, para gozar más. Cfr. Pl. Grg. 491e-ss. 
Ahora bien, estos temas no están completamente divorciados de la concepción y del lugar que tiene la amistad en el pensamiento de Epicuro. Si bien este tema no está abiertamente tematizado en la Carta, en ese contexto hay dos segmentos que lo evocan. Recordemos primero el pasaje 135, que cierra la epístola; allí se indica, después de caracterizar la filosofía, que al practicarla junto con otros que también filosofan el resultado es mejor; en ella habría una suerte de sinergia productiva para el sostenimiento y profundización de la reflexión:

Estas cosas, pues, y las que les son afines, medítalas noche y día dentro de ti $<y>$ con quien sea semejante a ti, y nunca, ni en vigilia ni en sueño, padecerás turbación, sino que vivirás como un dios entre los hombres. Pues en nada se parece a un viviente mortal el hombre que vive entre bienes inmortales

Sin mencionar explícitamente la philía, en este pasaje aparece insinuada su necesidad.

En el pasaje 127, por otro lado, Epicuro adelanta la idea de que ninguna situación futura es, en sí misma, tranquilizadora ni portadora de estabilidad:

Ha de recordarse que el futuro <ni es completamente nuestro> ni completamente no nuestro, a fin de que no lo esperemos con total certeza como si tuviera que ser, ni desesperemos de él como si no tuviera que ser en absoluto

En la medida en que muchas cosas imprevistas pueden suceder, el futuro, que no dominamos completamente, es una fuente de intranquilidad. Como decíamos más arriba, Epicuro piensa que hay cosas dependientes del hombre, otras dependientes de la fortuna ( $t y ́ k h e$ ) y otras incluso que se nos imponen con necesidad (133-134). En este espectro de eventos no dependientes de nuestra voluntad, la perturbación no tardará en aparecer. El hecho de no poder prever, de no saber cuál será la suerte propia -enfermedades, accidentes, etc.- crea sin duda una incertidumbre que daña la imperturbabilidad buscada. La amistad es introducida entonces también como un paliativo a esta debilidad de la psiquis humana. Pero para encontrar expresión de este puente entre amistad y ataraxía debemos abordar la lectura de algunas sentencias epicúreas. Veamos algunas de ellas:

a. MC 27: De las cosas que la sabiduría procura para la felicidad de la vida toda, la adquisición de la amistad es, con mucho, la mayor.

b. GV 23: Toda amistad es elegible por sí misma, pero ha llegado a su comienzo a partir de la utilidad (ophéleia).

c. GV 66: Padezcamos junto a nuestros amigos, no llorando, sino reflexionando (phrontízo).

d. GV 56-57: El sabio no sufre más cuando es torturado, sino cuando un amigo es torturado. $Y$ es capaz de morir por ese amigo. Pues, si traiciona al amigo, su vida toda quedará arruinada debido a su falta de fidelidad y se verá incapacitado para avanzar.

En estas sentencias aparece la conexión clara entre la sabiduría y la amistad. Aparece ampliada la perspectiva que leíamos en la Carta a Meneceo, sobre la reflexión en compañía de quienes son iguales y practican la filosofía. La felicidad es fruto de la percepción sabia del valor que tienen dichas relaciones. No filosofamos tan bien en abstracción de una comunidad de amistad. En la 
segunda sentencia citada, Epicuro agrega algo que será nodal para comprender su concepto de amistad: surge a partir de su utilidad (ophéleia). Es útil en tanto favorece la práctica mejor para la mejor vida. El fragmento ha suscitado debates, porque declara que la amistad es elegible por sí misma (heauté), cuando el mismo pensador dice que lo único elegible por sí mismo es el placer. En todo caso, es elegible -interpreta Aoiz (2013:23ss.)- en términos relativos a los placeres disfrutables por el hombre. Y en lo referente a nuestro interés, esta utilidad ha sido pensada como uno de los motores que -veremos más abajo-, en una perspectiva diacrónica, explican la fundación de la pólis. La amistad sería útil, en un sentido, por permitir una vida en la confianza y por ende procurar seguridad futura, cosa esencial a la hora de lograr la imperturbabilidad.

Los fragmentos que transcribimos como c. y d. explicitan la naturaleza de la verdadera amistad. El amigo sufre y se regocija con el amigo. El amigo es aquel con quien se reflexiona. La empatía que se da entre ellos produce también dolor, cuando el otro padece. Cuando leemos que la traición arruina la vida y que sólo en la fidelidad el hombre podrá avanzar, queda confirmado que la amistad fiel es sustrato de la red en la que el hombre vivirá confiado. En la GV 39, Epicuro insiste en que comprendamos correctamente el sentido de utilidad que implica la amistad:

No es un amigo ni quien busca continuamente la utilidad, ni quien jamás se junta <con otros>, pues el primero negocia la compensación con la gratitud, mientras que el segundo cercena la buena esperanza acerca del futuro.

La sentencia nos habla de dos tipos de estados que el hombre debe evitar, entre los cuales está la amistad auténtica, que el sabio debe fomentar; dichos estados son: el de la amistad interesada -falsa amistad-, y el de la vida de quien rechaza la compañía de otros. Quienes se acercan a otros para obtener ventajas no participan de una relación genuina; buscan a otro hombre, calculando la ventaja que pueden sacar de él. Los otros, ermitaños, ponen en juego su futuro. ¿Por qué la vida en soledad dañaría la perspectiva futura? Sin duda esto tiene que ver con la manera en que Epicuro piensa la amistad auténtica: ella proveerá de seguridad a la vida, a través de la confianza: los amigos acompañarán y cuidarán, en caso de necesidad. Quien logra establecer una relación de mutua gratitud -así caracteriza en este último fragmento a la amistad genuina-, crea un vínculo que lo protege. Esta protección es la salvaguarda de una vida inestable, insegura y desconfiada, todos estos claros factores de perturbación. Construir una red con amigos verdaderos, con los que se tiene real agradecimiento por compartir la reflexión, contribuye entonces a la felicidad. E. Brown (2009) propone leer el fragmento citado a la luz de la MC 40:
Quienes tienen la capacidad de obtener confianza (tò tharreîn) sobre todo a partir de sus prójimos, esos viven placenteramente unos con otros por poseer la garantía más duradera y, aun obteniendo una familiaridad satisfecha al máximo, no lloran como si sintieran comprensión ante la partida prematura de quien acaba de morir.

La idea de una confianza en el prójimo, presente en esta sentencia, vuelve a aparecer en la sentencia vaticana 15 :

GV 15: Estimamos nuestros caracteres como si fuesen asuntos particulares de nosotros mismos, tanto si somos virtuosos y envidiados por los hombres, como si no. De ese mismo modo es necesario que estimemos los caracteres de nuestros vecinos, toda vez que sean <caracteres> honrados. 
Los amigos, tanto como los vecinos honrados, procuran confianza. Parte de la tranquilidad que el sabio epicúreo busca reside en aceptar, no menos que prever, lo que puede venir en el futuro y desestabilizarlo. La confianza no puede sino formar parte de tal previsión.

Ya vimos en la Carta a Meneceo que el futuro no es completamente nuestro ni completamente extranjero a nosotros; ahora es la confianza (tharreîn) lo que abona la tranquilidad, tanto presente como futura. La amistad entonces no solo hace más fácil la reflexión, sino que es garantía de estabilidad. En esto se comprende que la soledad contemplativa no es aconsejable (GV 39).

Tal como expresa Bieda, la amistad epicúrea es una forma de relación "sofisticada", que permite cristalizar la actividad filosófica de la mejor manera realizable para el hombre. Es que

[Lo] que verdaderamente necesitamos no son los amigos en tanto hombres, pares, o seres humanos que nos acompañan materialmente, sino la confianza de tenerlos cerca que nos genera. (Bieda, 2015:79)

La contracara de la seguridad provista por el amigo es el compromiso propio de no abandonarlo. Epicuro piensa así un terreno sólido sobre la que se asienta la ataraxía. 4

El planteo comienza a volverse problemático cuando leemos afirmaciones como la siguiente, que transmite Diógenes Laercio:

La compañía (synousía) nunca es de utilidad, incluso en caso de que no dañe. Ni debe el sabio -dice Epicuro en los Problemas y en los tratados Sobre la Naturaleza- casarse ni tener hijos; sin embargo, en la vida hay circunstancias que lo desvían hacia el casamiento.(D.L. X 119)

El término synousía, que traducimos aquí como 'compañía', alude tanto a pasar tiempo con otros, como al intercambio sexual. Como quiera que optemos por traducirlo aquí, no se trata de una relación que incluya la philía, que, en términos generales, es una synousía. La synousía parece aludir aquí más particularmente a la relación del sabio con una mujer, y a la posibilidad de dedicar parte de su vida a la conformación de una familia. Casarse (gaméo) y procrear (teknopoiéo) son prácticas desaconsejables para el epicúreo porque-podemos inferir-, en primer lugar, proveen placeres somáticos y, por otro, a nivel psíquico producen preocupaciones evitables. Diógenes Laercio y Filodemo aportan algunos datos sobre la valoración de Epicuro de la vida práctica y del compromiso del sabio con su comunidad. Como ya dijimos, debe apartarse de las cuestiones de poder y de la administración, tanto en la pólis como en el ô̂kos, pero parece haber admitido cierta participación de la vida pública: la observancia de rituales religiosos y mistéricos comunes son aceptables, e incluso formaron parte de las propias prácticas de Epicuro. ${ }^{5}$

El punto de inflexión entonces, a partir del cual podemos comenzar a comprender la posición del filósofo sobre la pólis, está en la valoración -negativa- de un tipo de placer ya presente en los elementos básicos que la constituyen: la

4 Fr. 584: <El sabio> se alzará en armas contra la fortuna, y no abandonará a ningún amigo. 
familia, y su relación con los placeres vanos. ${ }^{6}$ La amistad genuina no incluye ningún tipo de preocupación, sino, mejor, la posibilidad de cultivar situaciones de seguridad, de protección, y que potencialmente construyen un futuro de tranquilidad y estabilidad.

\section{Amistad sin comunidad política}

En directa relación y coherencia con esta desestimación de las relaciones familiares, comienza a tener sentido lo expresado en las sentencias siguientes:

e. Fr. 8: <El sabio> tampoco participará en política.

F. Fr. 548: Ni la multitud de riquezas, ni la importancia de las ocupaciones, ni ciertos cargos políticos ni poderes poseen en sí la felicidad o la buenaventura; más bien la poseen la ausencia de sufrimiento, la docilidad de nuestras pasiones y la disposición del alma que ha definido lo que se da conforme a la naturaleza.

El entorno político implica inestabilidad, conflicto de poderes, multiplicidad de obligaciones y ocupaciones, en síntesis, alejamiento de una situación de ataraxía. Es por esto que no está vista por Epicuro como una condición natural; es negativa y debe ser evitada. En la máxima se excluye lo político y sus implicaciones, de lo que es "conforme a naturaleza" (katà phýsin). Y, si bien la amistad también apareció fundada en la utilidad y no en la naturaleza, es elegible por sí misma.

Igual que la amistad, la justicia es convencional. En la máxima capital 32, el filósofo la caracteriza como una capacidad de pactar. No hay algo naturalmente justo, sino que aquello llamado 'justo' lo es por convención. Este pacto (synthéke) es por tanto dependiente de disposiciones de los hombres. Recordemos la MC 32:

A propósito de cuantos seres vivos no son capaces de hacer pactos acerca de no dañarse recíprocamente unos a otros ni ser dañados, para ellos no existe nada justo ni injusto. Del mismo modo, también ocurre eso con los pueblos que no son capaces o no quieren hacer pactos acerca de no dañar ni ser dañados.

Además de declararse la naturaleza contractual de la justicia, se explicita aquí la esencia de aquello que será llamado 'justo': que los hombres que conviven no se dañen mutuamente. Quienes no son capaces de realizar y respetar estos pactos, sean animales o pueblos salvajes, están condenados a dañarse y -no se puede pensar otra alternativa- a aniquilarse. La sentencia 33 completa esta idea:

La justicia no es algo en sí mismo, sino cierto pacto (synthéke) acerca de no dañar ni ser dañado en los tratos recíprocos, en cualquier momento, en cualquier región.

El hecho de que la justicia no sea algo en sí (ti kath' heautó) indica que no hay una única definición de 'justo'; así, su esencia consiste en procurar lo que, en 
cada caso, lleva a la supervivencia de un pueblo, a partir de establecer qué puede y qué no puede hacerse. Qué es concretamente eso que puede o no puede hacerse, será patrimonio de cada pueblo y de cada momento histórico, y se plasmará en leyes, siempre revisables y renovables, de acuerdo con las exigencias de una realidad dinámica. Al mismo tiempo, en la $\mathrm{MC}_{34}$, cuando se caracteriza la injusticia, ${ }^{7}$ Epicuro declara que no es en sí misma un mal; en todo caso, lo negativo es el temor que se desprende de haber cometido algo que la ley prohíbe, y saber que el castigo puede ser sufrido en cualquier momento. Entonces es la perspectiva de un castigo futuro lo que hace mala a la acción, pero de ningún modo la injusticia misma.

Epicuro hace residir la tranquilidad -no la más estable, pero una también ponderable- en la seguridad de que no vamos a recibir daño (blápto), si no lo hacemos a otros. En esto consiste la justicia: en el pacto, en el establecimiento y el compromiso de no dañar, 'para' no ser dañados. Es interesante -como observa Aoiz (2013)- que Epicuro no habla de la injusticia de dañar, sino que lee la situación en términos de defensa, de preservación. La búsqueda de esta justicia es lo que fundaría a la sociedad toda.

Aunque Epicuro no dice demasiado sobre el origen mismo de una organización política fundada en el pacto, contamos con testimonios de Hermarco, discípulo y primer filósofo a la cabeza del Jardín tras la muerte de aquel, en los que aparece la idea de una evolución de la comunidad, que hizo necesario el pacto entre los hombres para establecer lo justo. ${ }^{8}$ En sus orígenes, la comunidad simple de hombres comenzó a desarrollar un sentimiento de compasión frente al mal sufrido por el prójimo -extensión hecha de la agresión sufrida de parte de los animales salvajes, dice Hermarco-, que permitió desarrollar el sentimiento de amistad. La amistad se vuelve entonces primaria respecto de la elaboración del pacto de justicia. ${ }^{9}$ Por otro lado, Hermarco habla de la necesidad, ya en el marco social, de la educación y del castigo como elementos que apuntalan la convivencia. Habría establecido así tres tipos de hombres, caracterizados respecto de estos parámetros: quienes no necesitan leyes, pues no son capaces de dañar a otro -como el sabio epicúreo-; otros, que están en camino de ser como ellos, y que pueden por tanto moderarse a través de la educación; finalmente, quienes no son capaces de moderar sus acciones salvajes por medio de la educación, para los que está reservado el castigo.

En el planteo de Epicuro este desarrollo está ausente. A lo sumo, como en la MC 34 que ya recordamos, ${ }^{10}$ contamos con la idea del gran riesgo que acompaña a la acción injusta: la perspectiva de recibir un castigo. Epicuro advierte varias veces sobre este punto: lo injusto no es en sí mismo un mal; el mal es la intranquilidad que supone el castigo potencial, que se instala ya a partir del momento en que se realizó el acto injusto. De este modo, la amistad y la justicia habrían tenido una génesis común: la búsqueda de la aspháleia, de una seguridad que es básica para la vida feliz. En una línea argumentativa productiva, Aoiz recuerda la idea aportada por el epicúreo Lucrecio en su explicación sobre la necesidad humana de realizar pactos:

7 MC 34: "La injusticia no es en sí misma un mal, sino que radica en el temor surgido de una conjetura: ¿pasará desapercibida a quienes han sido designados para castigar por tales motivos?".

8 Cfr. Long (2006:194-197).

9 Hermarchus ap. Porph. Abst. 1.12.2.

10 Cfr. nota 7 supra. 
En su reconstrucción racional del origen de la justicia, Lucrecio destaca que el advenimiento del pacto en que se funda se hace posible gracias a un paulatino proceso de suavización, molescere, física y psicológica. Del rudo y solitario hombre primitivo debido al uso del fuego y de moradas, y al establecimiento de la vida en familia, que le lleva a establecer relaciones de amicities con los vecinos y pactos, foedera, para proteger a los débiles. (2013:23)

Tanto los pactos a nivel político como la amistad a nivel comunitario forman parte de un plan racional para la vida tranquila. La perspectiva de su génesis da cuenta de la inspiración común que los anima. Se trate de un castigo o de un desamparo en la vejez, en ambos casos es la perspectiva de un futuro tranquilo lo que lleva al sabio a percibir la necesidad de establecer relaciones amigables con los demás.

En el ámbito público, el temor de la inestabilidad que generaría la sombra de una venganza por una injusticia cometida es lo único que constituye una contravención a la justicia pactada: "el injusto está lleno de gran turbación" (MC 17). En este mismo sentido leemos la máxima 35, porque la intranquilidad se liga allí directamente a una conciencia que nunca hallará paz, por saber que está en deuda con quien padeció la injusticia realizada:

No es posible que quien realiza a escondidas alguna de las cosas que pactó con otros con vistas a no dañar ni ser dañado confíe en que pasará desapercibido, aun cuando haya pasado desapercibido miles de veces hasta el presente, pues es incierto si también pasará desapercibido hasta la conclusión <de su vida>.

La máxima capital 36 confirma la naturaleza contingente de lo justo, y lo coloca en la perspectiva de una pólis cambiante; lo díkaios depende exclusivamente de lo que una comunidad haya determinado útil, y será justo exclusivamente 'durante el tiempo' que eso le resulte útil:

Conforme a un criterio común, lo justo es lo mismo para todos, pues consiste en algo conveniente que se da en la comunidad de unos con otros. Pero del criterio particular de una región y de cuantas condiciones se dan en cada momento particular, no se sigue que lo mismo sea justo para todos.

Lo conveniente (symphéron), como lo útil, se cristaliza en la convención. La naturaleza contingente y particular del pacto se hace nuevamente patente, en este caso bajo la perspectiva de una situación propia de cada contexto de acuerdo. En la MC 38, Epicuro vuelve sobre esta naturaleza contingente del pacto:

Entre las cosas consideradas justas, aquello que testimonia lo que es conveniente en las necesidades propias de la comunidad de unos con otros tiene un carácter justo, tanto si resultara lo mismo para todos, como si no. Pero si se estableciera alguna ley, y esta no resultara conforme a lo conveniente para la comunidad de unos con otros, esto ya no contiene la naturaleza de lo justo. Y si lo conveniente conforme a lo justo cambiara, pero durante algún tiempo se armonizara con nuestra prenoción, no sería menos justo durante ese tiempo para quienes no se confunden a sí mismos con voces vacías, sino que observan en dirección a los hechos.

Lo pactado por diferentes comunidades puede ser lo mismo, o no. Pero, incluso en el marco de una misma comunidad, lo que se ha establecido como ley, lo 
que resulta del pacto, puedo volverse inoperante en un momento diferente al que se instauró. De este modo, la ley 'ya no será justa'. El criterio último para la determinación de lo justo es netamente pragmático.

En una lectura muy estimulante, Brown (2009:191ss) descubre que, a pesar de la negativa explícita de Epicuro de participar de la vida política, asume la necesidad de que exista un marco político que dé estabilidad y una base social mínima a la comunidad de amistad de filósofos, que propone. Si no existiera tal supuesto -argumenta el crítico-, una comunidad que se postula en contra de crear familias y tener hijos, como es el caso del epicureísmo, estaría destinada a la pronta extinción completa. Otro tanto afirma Brown que debe pensarse acerca del ataque de comunidades exteriores, respecto de la comunidad de amistad. Frente al argumento $a b$ silentio por parte de Epicuro sobre la posibilidad de que exista una comunidad de amistad fuera de todo ámbito político, Long también sostiene que un estado presocial no hubiera podido sostener una vida tal como Epicuro la propone: "no estaría disponible la subsistencia y seguridad mínima" (2006:180). Probablemente estas especulaciones trascienden los intereses especulativos de un Epicuro preocupado por ayudar al hombre con inquietudes filosóficas a encontrar un camino para su mejor realización.

\section{A modo de síntesis}

Algunos de los críticos mencionados consideran que Epicuro concibió una comunidad de amistad como un grupo de naturaleza parasitaria, ${ }^{11}$ que se sirvió de un ámbito político y social proveedor de una estabilidad básica y necesaria para el bienestar humano, sin realizar en ella ningún aporte, o-peor- sin considerarla más que como una especie de 'gran proveedor'. Después de lo que hemos señalado hasta aquí, y a la luz de estas apreciaciones sobre el valor y la consistencia de la propuesta epicúrea, volvemos a la pregunta inicial de nuestro trabajo, sobre la compatibilidad de que el hombre se aleje de la vida política, pero se comprometa con la vida en amistad -siendo ésta posible sólo en un entorno político. Como vimos, para intentar responder dicho cuestionamiento debemos entender lo que el filósofo concibe como justicia, porque a partir de este concepto aparecerán datos tanto sobre la cuestión política como sobre la comunidad de amistad y su utilidad. Diógenes Laercio transmite algunos datos que complementan nuestras observaciones anteriores. Nos cuenta el doxógrafo que Epicuro consideró positivo realizar algunas actividades relativas a lo común, en la medida en que le proporcionaran medios para vivir: "[el sabio] podrá servir a un monarca de acuerdo a las circunstancias" (X 121b5) y tener una presencia pública. Más allá de que en el Jardín había espacio para el autoabastecimiento de alimentos, por ejemplo, Epicuro parece haber tomado en cuenta

las nuevas condiciones sociopolíticas, es decir bajo la forma del servicio a un monarca en el momento oportuno (en kairôi) (...); podrá hacer lecturas públicas, aunque no por su voluntad (hékonta). Ello redundaría sin duda en la autarquía del filósofo. (Nova Contreras, 2002:46-47)

Es posible tomar parte activa de la vida política, comprometiéndose con el ejercicio concreto del poder; pero también es posible una cierta participación 
en lo común, habilitada sólo cuando se trate de procurarse bienes para una subsistencia tranquila, segura y autónoma. Considerando estas declaraciones y recordando, junto con ellas, el cuidado que Epicuro pone al escribir su testamento - detallando qué debe hacerse con cada una de las cosas que posee y lo que cada uno de sus amigos debe recibir en carácter de herencia-, es indudable que para el pensador hay aspectos políticos ${ }^{12}$ de la vida cotidiana que no molestan, e incluso favorecen la consecución de la ataraxía. Visto así el ámbito público, la exhortación a apartarse de la vida política y la íntima relación que intentamos mostrar entre amistad y nacimiento de orden jurídicopolítico no implican necesariamente contradicción. Su condena sólo compete a vivir dedicado a asuntos políticos, no a realizarlos esporádicamente, cuando sea conveniente.

Epicuro expresa, pues, en términos teóricos cómo es la vida que funciona de manera perfecta: vivir en una comunidad donde reine el agradecimiento y la vocación genuina de acompañar a los pares que filosofan. Mientras tanto, una vida práctica compleja se desarrolla alrededor. Esta no debe atrapar al sabio -él no debe comprometerse, por ejemplo, como pretendió Platón, con el gobierno de la pólis-; pero, en la medida en que su participación ocasional en la vida pública le procure medios para su estable tranquilidad, debe ser atendida. No irá voluntariamente hacia ella, pero tampoco luchará en su contra. En este difícil, inestable y azaroso lugar en que se establece la vida humana, Epicuro sólo atinó a advertirle al sabio lo que sería mejor para él. Pero su filosofía no se asienta en la reflexión 'sobre' la vida política ni sobre sus defectos, ni se detiene a evaluar la necesidad que su propia comunidad de amistad tiene de un entorno pacífico y estable para poder existir. No hubo lugar ni interés en Epicuro para una reflexión política en sí misma. Las referencias marginales que conservamos al respecto dan fe de ello.

12 Entendemos 'político' en su sentido más llano, es decir lo común, lo propio del espacio compartido con los demás ciudadanos. 


\section{Q Bibliografía}

» Aoiz, J. (2013). "Prolepsis y justicia en el epicureísmo". Argos 30.48, 15-42.

" Arrighetti, G. (ed.) (1960). Epicuro, Opere. Torino: Einaudi.

» Bailey, C. (ed.) (1926). Epicurus: The Extant Remains. Oxford: Oxford University Press.

» Bieda, E. (2015). Epicuro. Buenos Aires: Galerna.

" Brown, E. (2009). "Politics and society”. En: Warren, J. (ed.). The Cambridge Companion to Epicureanisms. Cambridge: Cambridge University Press, 179-196.

» Long, A.A. (2006). From Epicurus to Epictetus. Oxford: Oxford University Press.

» MacPherson, C.B. (1962). The Political Theory of Possessive Individualism. Oxford: Oxford University Press.

"Mondolfo, R. (2010). La conciencia moral de Homero a Demócrito y Epicuro. Buenos Aires: Eudeba.

" Nova Contreras, M. (2002), "La 'economía' del Filósofo. Epicúreos y estoicos helenísticos acerca del vivir filosóficamente", Synthesis 9, 39-51.

» O'Keefe, T. (2001). "Is Epicurean friendship altruistic?", Apeiron 34, 269-305.

» Oyarzún, P. (1999). "Epicuro: Carta a Meneceo. Noticia, traducción y notas . Onomázein 4, 403-425. 